\title{
Process Data Management Based on Teamcenter Manufacturing
}

\author{
Bin Wang ${ }^{1, a}$ and Xinyan Lin ${ }^{2, b}$ \\ ${ }^{1}$ UGS College, Yancheng Institute of Technology, Yancheng, China \\ ${ }^{2}$ School of Automobile and Traffic Engineering, Jiangsu University, Zhenjiang, China \\ awangbin@ycit.cn, ${ }^{\text {b3}} 303693182 @ q q . c o m$
}

Keywords: Teamcenter, Process Data Management, Process Design

\begin{abstract}
An application of Teamcenter Manufacturing (TCM) in Process Data Management is presented in this paper. Being based on the advantage of traditional process design method, TCM gives full play to the efficacy of combination among generation, receiving, maintaining, sending and application of process information, satisfies the demands of process information sharing among different users, and provides an effective method to achieve the digitization of design, manufacturing, detection and assembly during the total life cycle of products.
\end{abstract}

\section{Introduction}

Process design is a key link between product design and product manufacturing. Simultaneously, it has close relationship between Quality Assurance (QA), Production Activity Control (PAC) and other departments. Because traditional process design mainly rely on the technical level, experience, habits of technologists, it is inefficient with strong personality and it already less and less adapts to the modern manufacturing mode of multispecies, small amount and short delivery time. Process design has become one of the bottlenecks of restricting the development of enterprises and more and more attention is paid to it. How to free technologists from heavy searching information and filling in process cards manually, and make full use of their rich design experience at the same time, has become a problem which enterprises have to solve.

As an important part of Teamcenter products, TCM is an industry solution put forward for manufacturing by Siemens. As a software system gathering modeling, planning, analysis and simulation of manufacturing process as a whole, TCM relates product data, process operation, manufacturing resources and manufacture feature to model process, plans and simulates manufacturing process of parts, workflow of assembly line, workflow of plant and product activities of enterprise from local to the whole, thus achieve the goal of optimizing process plan. Teamcenter Manufacturing Process Planner (TCMPP) can significantly improve process design method and management process, promote the level, efficiency and quality of process design, and finally shorten development cycle and production cycle of products.

Many studies on Teamcenter have been conducted by scholars. Jiapeng Li et al. presented an application of Teamcenter in product structure management [1]. Yansong Gao and Jing LI performed a research of product lifecycle management software based on Teamcenter [2]. Some other applications and researches are also conducted in different fields [3,4].

\section{System General Framework of TCM}

As a manufacturing process management platform, TCM achieve digitization, networking and flow control of process planning through process design and data, flow, resources and changing management. Technologists use Manufacturing Structure Editor (MSE) of TCM to redact process route and build Bill of Process (BOP) structure tree which includes all process information. Figure 1 shows the interface of MSE.

The application layer of Teamcenter provides many functions, including document management, product structure management, operation flow management, process planning, process data management, documents output, etc. Data access layer directly interacts with the operating system 
and database, provides reliable and efficient data access, object management, text search, and some other basic functions for the application layer.

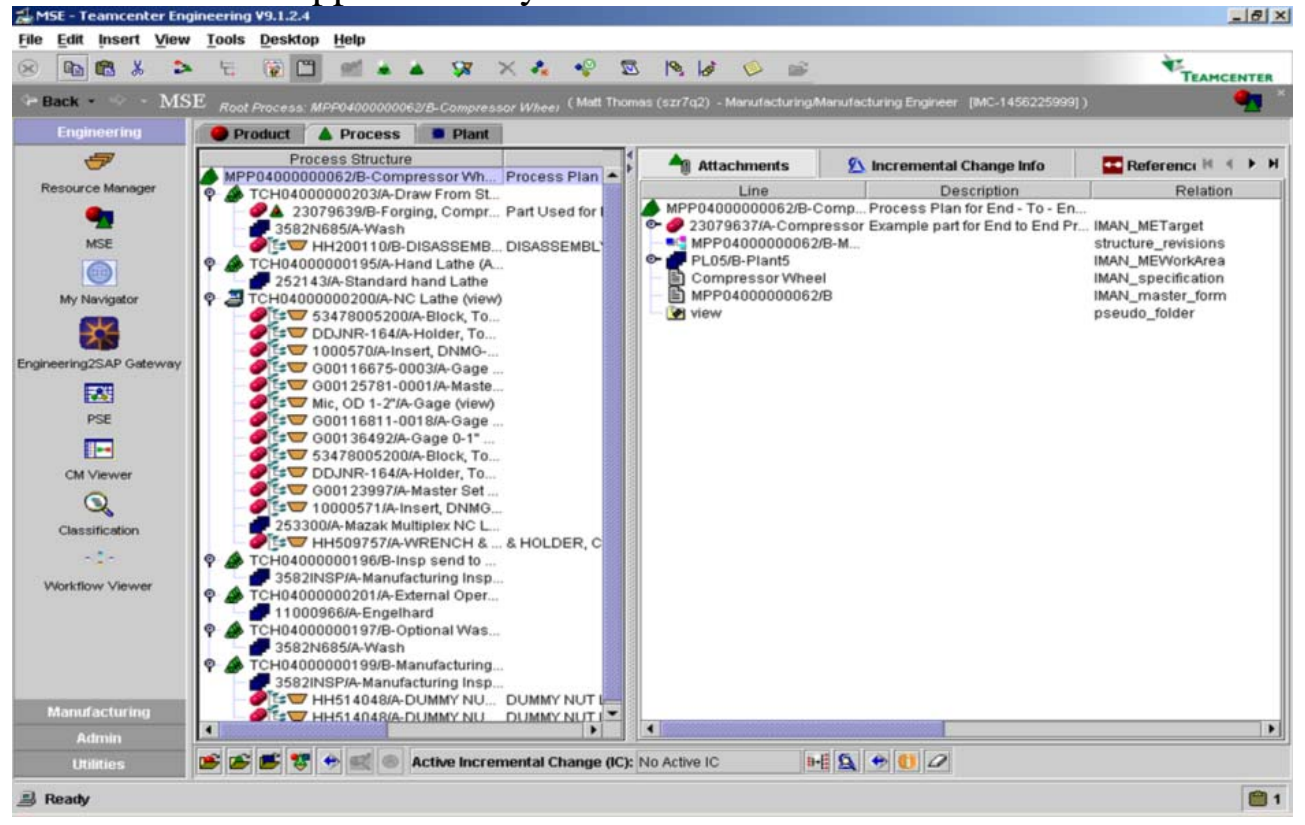

Fig. 1 Interface of MSE

\section{BOP Structure Design}

BOP is a kind of dendriform process structure which is constitutive of parts, process and plant connected through a special relationship according to process route sequence. All information of process can be seen under the structure tree including table of process attribute, process instruction card, assembly parts, cutters, fixtures and equipment, etc. Figure 2 shows the BOP model and the management interface of BOP.
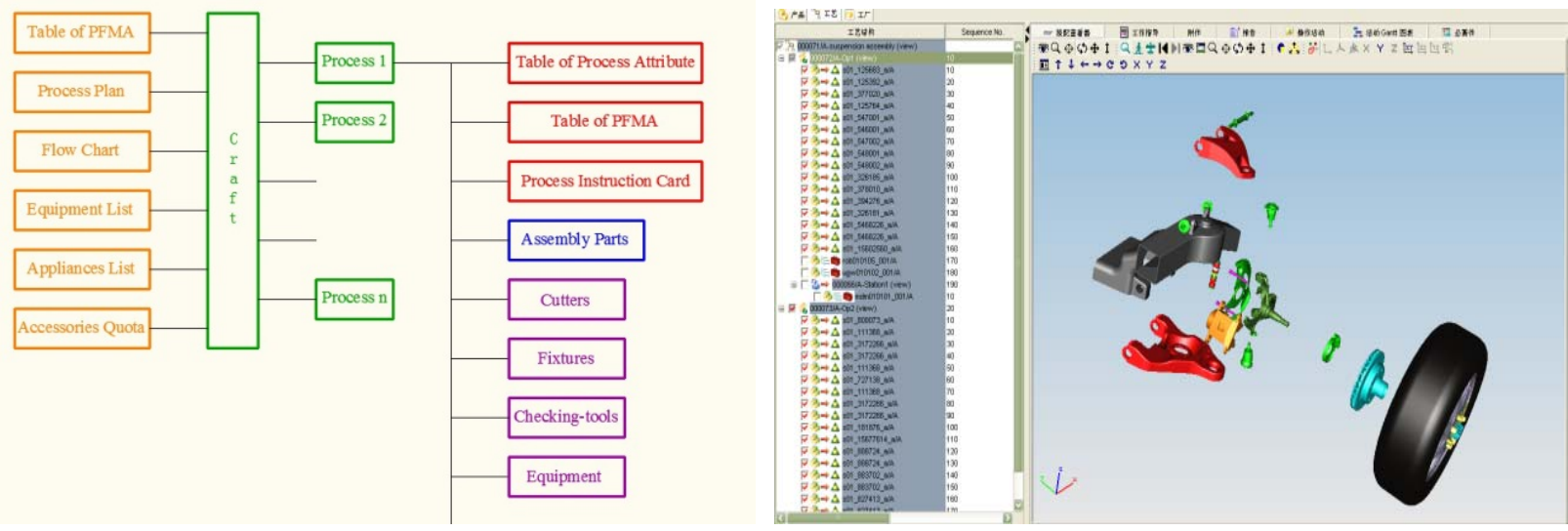

Fig. 2 BOP Model and Management Interface of BOP

\section{Process Resources Management}

The accumulated process resources are rare wealth for enterprises. Enterprises can use the Manufacturing Resources Management to manage the precious process resources. Process resources can be divided into two parts, one is process knowledge database such as typical process database, process parameters database, cutting parameters database, etc, and the other part is rock-bottom manufacturing resources such as equipment, general tools, special tools, etc. Technologists can efficiently manage process knowledge and manufacturing resources by using the In-class management function of TCM which is a highly integrated, easy-to-grasp and easy-to-use software system to shorten process design cycle and promote process design accuracy and efficiency. 


\section{Fast Process Design Based on the Typical Process}

Providing enterprises with the environment, platform and tools of knowledge management is a very important function of TCM. Fixed and typical process can be accumulated as knowledge and stored in the repository in the form of template for future reference or direct reusing. When designing the process, technologists can gradually manually create process structure according to the features of products or parts, also can choose a typical process of the products or parts as a template from the process repository to automatically generate BOP structure and then make appropriate adjustments.

According to the plants layout of enterprises, the plants, workshops and equipment models can be defined based on the Product, Process, Plant, Resources (3PR) idea. Then associate equipment with plants layout and endow equipment the attribute of plants layout, thus plants structure can be used during process design. Finally relate process panel point with workshop area and appoint operation location and equipment for the process panel point. Figure 3 shows the 3PR model.

TCM establishes some reference relationship between the above design and 3PR model. Technologists or operators can quickly, effectively and accurately locate the needed objects through the relationship. Thus the process design efficiency will be significantly improved and the design cycle will be shortened.

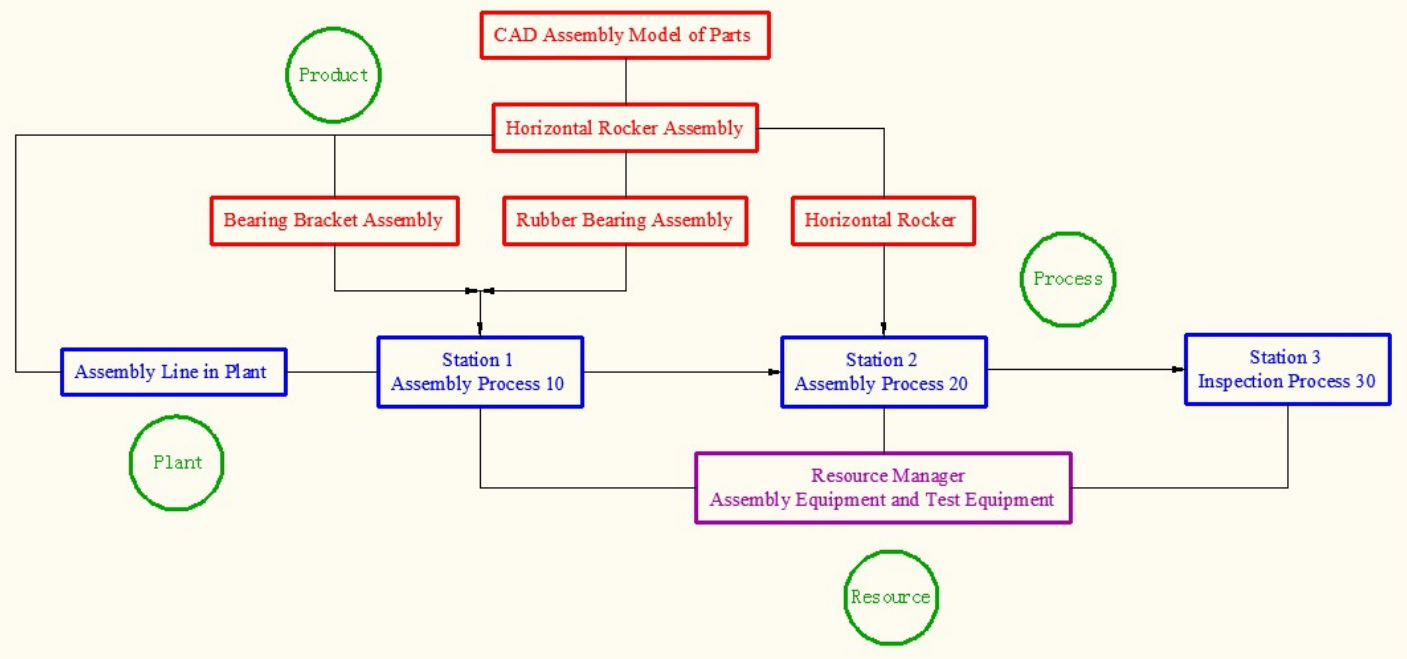

Fig. 3 3PR Model

\section{Summary}

Aim at the actual demand of process data management, flow management and various informatizaiton application systems integration of modern enterprises, an application of Teamcenter Manufacturing in Process Data Management is presented in this paper. The application of TCM plays a significant role in improving process design methods and management, promoting process design level, efficiency and quality, shortening product development cycle and manufacturing cycle.

\section{Acknowledgment}

The project was supported by research fund of Key Laboratory for Advanced Technology in Environmental Protection of Jiangsu Province.

\section{References}

[1] LI Jiapeng, WANG Haocheng, LI Yusheng and YUAN Xiaoliang, Product Structure Management Based on Teamcenter Express. Journal of Shandong University of Technology (Natural Science Edition), 22 (5) (2008) 85-87. 
[2] GAO Yansong and LI Jing, The Application and Research of Product Lifecycle Management Software Based on Teamcenter. Computer Application and Software, 23(12) (2006) 61-63.

[3] Ahmed Al-Ashaab, M. Molyneaux, A. Doultsinou, B. Brunner, E. Martínez, F. Moliner, V. Santamaría, D. Tanjore, P. Ewers, G. Knight, Knowledge-based Environment to Support Product Design Validation. Knowledge-based Systems, 26 (2012) 48-60.

[4] J. Cable, Teamcenter 8 aims to drive PLM productivity, Industry Week/IW 258(8) (2009) $42-44$. 